\title{
Evaluation of a national surveillance unit
} Madlen Gazarian, Katrina Williams, Elizabeth Elliott, Kerry Chant, Helen Longbottom,
Craig Mellis, Terry Nolan, R K Oates, Alan Ruben
The Australian Paediatric Surveillance Unit, and the University of Sydney, Australia M Gazarian

K Williams

E Elliott

Clinical Epidemiology Unit, Royal Alexandra Hospital for Children, Sydney, Australia C Mellis

Department of Paediatrics and Child Health, University of Sydney

R K Oates

South Western Sydney Public Health Unit, Sydney, Australia K Chant

Commonwealth Department of Health and Family Services, Canberra, Australia H Longbottom

Clinical Epidemiology and Biostatistics Unit, Royal Children's Hospital, Melbourne, Australia

T Nolan

Department of Paediatrics, Royal Darwin Hospital, Australia

A Ruben

Correspondence to: Dr E Elliott, The Australia Paediatric Surveillance Unit, PO Box 3515, Parramatta 2124, NSW, Australia. email:apsu@nch.edu.au

Accepted 7 July 1998

\begin{abstract}
Aim-The Australian Paediatric Surveillance Unit (APSU) facilitates national active surveillance of uncommon childhood conditions. This study assessed whether it fulfilled its objectives and satisfied criteria established by the Centers for Disease Control and Prevention (CDC) for evaluating surveillance systems. Methods-Anonymous questionnaires were sent to users of the system, individual studies were reviewed, and data were collected from independent sources. Results-Seven hundred and sixty six clinicians, 48 investigators, and 15 public health professionals responded to the questionnaires. Clinicians reported that the APSU was useful, $33 \%$ saying information provided by the APSU informed or changed their clinical practice. Most $(88 \%)$ reported that completing monthly report cards was not a burden. Impact on policy development was limited by suboptimal dissemination of information to public health professionals. Flexibility and timeliness were limited by design. Estimated sensitivity of APSU studies ranged from $92 \%$ (congenital rubella) to $31 \%$ (drowning/near drowning). Positive predictive value of notified cases was over $70 \%$ for most studies.

Conclusion-The APSU fulfils most of its objectives and meets CDC criteria salient to these. Ways in which the APSU could be improved have been identified, as have methodological challenges and limitations in applying CDC guidelines to this type of unit.

(Arch Dis Child 1999;80:21-27)
\end{abstract}

Keywords: paediatric surveillance unit; evaluation; questionnaire

The Australian Paediatric Surveillance Unit (APSU) is a national active surveillance system for uncommon childhood conditions. Established in June 1992, it was incorporated as a unit of the Australian College of Paediatrics and commenced operation in May 1993. Unique in Australia, the APSU was modelled on the British Paediatric Surveillance Unit (BPSU), ${ }^{1}$ and is one of 11 national paediatric surveillance systems worldwide. None has been evaluated systematically. The aim of our study was to evaluate whether the APSU fulfilled its stated objectives and conformed with guidelines developed by the Centers for Disease Control and Prevention (CDC) for evaluating surveillance systems. ${ }^{2}$ We present the results of the evaluation and some problems encountered in applying CDC guidelines to this type of surveillance unit.

\section{Methods}

APSU

The operation of the system, summarised in fig 1 , has been described previously. ${ }^{3}$ In brief, the reporting source (mailing list), which includes all Australian clinicians specialising in child health, are sent a monthly, reply paid report card listing the conditions currently being studied (fig 2). They are asked to indicate whether they have seen a child in the last month with any of these conditions. Researchers responsible for each condition (investigators) are notified monthly by the APSU of positive reports. Investigators then obtain demographic and clinical details from reporting doctors by postal questionnaire and are responsible for analysis and publication of data. Figure 3 lists the objectives of the APSU and table 1 lists the conditions that are monitored. Any individual or organisation can apply to have a condition monitored by the APSU and applications are reviewed by a scientific panel. Most conditions are monitored for three years, although those of public health significance and with low case notification rates might be monitored for longer.

\section{CRITERIA FOR EVALUATION}

We considered all attributes suggested by the CDC guidelines ${ }^{2}$ (fig 4). The only objective of the APSU not considered by the CDC guidelines was facilitation of national collaborative research, which was considered in the usefulness section. To address the areas recommended by the CDC, we used different forms of information about different components of the APSU. Results are presented according to the framework suggested by the CDC.

\section{DATA COLLECTION}

Questionnaire based surveys of the users of the system

We developed three anonymous questionnaires, which were sent to clinicians on the mailing list $(n=954)$, investigators $(n=51)$, and public health professionals working in the areas of policy development with respect to child health or communicable diseases $(n=18)$. Questionnaires incorporated quantitative and qualitative measures to assess whether the objectives of the APSU were being met and whether the system fulfilled selected CDC criteria. Data were analysed using the "statistical package for the social sciences". 


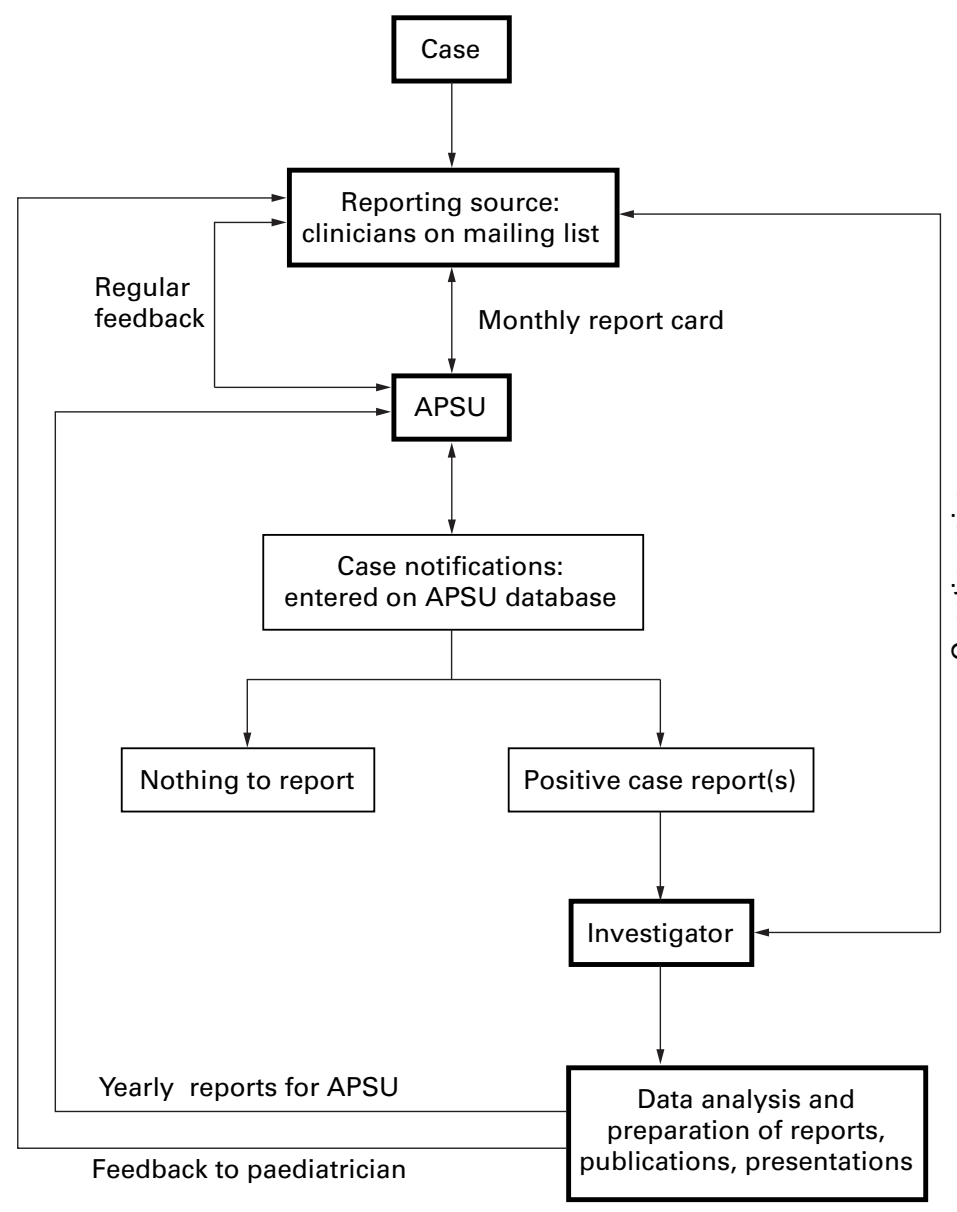

Figure 1 The operation of the APSU

No Postage stamp required if posted in Australia

Reply Paid 300

Australian Paediatric Surveillance Unit

Level 2, Clinical Sciences Building

PO Box 3515

Parramatta NSW 2124
October, 1996

\section{APSU REPORT CARD}

Dr's Code No. [

NOTHING TO REPORT: (Tick box)

NUMBER OF CASES: (Place No. in space provided)

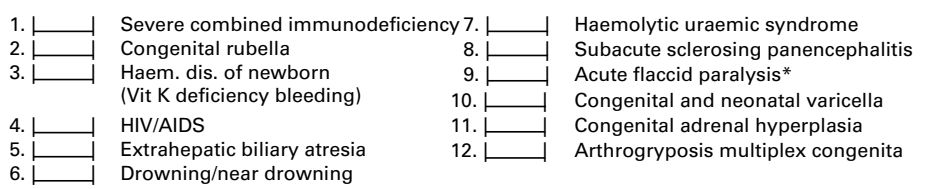

If you report a case please keep patient details on the YELLOW report sheet in your BLUE APSU folder for later reference.

* Report immediately by telephone to Dr. Herceg (06)289 8638. Also indicate the case on your report card. N.B. Acute flaccid paralysis includes wild and vaccine acquired poliomyelitis, Guillain-Barre, transverse myelitic paralysis etc.

Figure 2 The reply paid reporting card.
Review of individual studies conducted through the APSU

We assessed questions relevant to the overall evaluation that could not be addressed by considering the system as a whole by examining data from individual studies, as supplied to the APSU for its annual reports. Information reviewed included questionnaire response rates and study outcomes.

Independent data

We sought data from alternative sources for selected studies to validate case ascertainment through the APSU and to estimate its sensitiv@ ity. Calculating sensitivity was often a problem owing to a lack of an alternative source or limitations in the type of information available.

\section{Results}

Seven hundred and sixty six (80\%) clinicians on the mailing list, 48 investigators, and 15 public health professionals responded to the survey questionnaires.

PUBLIC HEALTH IMPORTANCE

Conditions are only accepted for study through the APSU if they are uncommon (and hence require national data collection to provide meaningful information), of public health importance, and are seen by those on the mailing list. Data should not be available from another source. Some are associated with substantial morbidity or mortality and/or result in high utilisation of health resources, while others are communicable or preventable.

THE SYSTEM

The mailing list, which is updated at least annually, can be adapted to target a broader group of respondents relevant to conditions listed-for example, child psychiatrists were included during studies on Rett syndrome and childhood dementia. Poor responders are also reviewed periodically.

\section{USEFULNESS}

Does the system detect trends signalling changes in the occurrence of disease?

The APSU can monitor trends in disease incidence, management, and outcome over time by monitoring a disease over several years or by performing cross sectional studies separated in time. Case identification is not usually sufficiently timely to allow detection of disease outbreaks or epidemics as they occur because of the inherent delay in receiving notifications (report cards are sent at the end of each month and their return time is variable). However, by providing background information on haemolytic uraemic syndrome cases occurring nationally, the system facilitated the investigation of an epidemic in South Australia that occurred after the condition had been listed on the monthly card. ${ }^{5}$

Does the system provide estimates of the magnitude of morbidity and mortality related to the health problem under surveillance? Clinical information collected through the APSU enables detailed assessment of acute 
Primary objectives

- To document the incidence, geographical distribution, clinical features, current management, and short term outcome of selected uncommon childhood conditions or their complications in Australia

Secondary objectives

- To provide a mechanism for national collaborative research

- To issue updated clinical and diagnostic information about conditions being studied to clinicians caring for children

- To disseminate information acquired by the unit that will best guide practice, appropriate prevention strategies, and optimal health resource allocation

Figure 3 Objectives of the APSU.

Table 1 Conditions monitored by the APSU up to the end of 1996

\begin{tabular}{|c|c|c|}
\hline Conditions under surveillance & $\begin{array}{l}\text { First month of } \\
\text { reporting }\end{array}$ & $\begin{array}{l}\text { Last month of } \\
\text { reporting }\end{array}$ \\
\hline Acute flaccid paralysis & March 95 & \\
\hline Arthrogryposis multiplex congenita & January 96 & \\
\hline Childhood dementia & May 93 & June 95 \\
\hline Congenital adrenal hyperplasia & August 95 & \\
\hline Congenital and neonatal varicella & March 95 & \\
\hline Congenital rubella & May 93 & \\
\hline Drowning/near drowning & May 93 & December 96 \\
\hline Extrahepatic biliary atresia & May 93 & December 96 \\
\hline Haemolytic uraemic syndrome & July 94 & \\
\hline Haemorrhagic disease of the newborn ${ }^{\star}$ & May 93 & \\
\hline HIV/AIDS + & May 93 & \\
\hline Kawasaki disease & May 93 & June 95 \\
\hline Rett syndrome & May 93 & April 95 \\
\hline Severe combined immunodeficiency $\ddagger$ & May 95 & December 96 \\
\hline Subacute sclerosing panencephalitis & January 95 & \\
\hline
\end{tabular}

*Vitamin $\mathrm{K}$ deficiency bleeding, including haemorrhagic disease of the newborn.

†Includes perinatal exposure to HIV.

¥Included in primary immunodeficiency study from January 1997

Description of the public health importance of the conditions studied

Description of the system

Objectives of the system

The conditions under surveillance

Flow chart of the system

The components and operation of the system

Indication of the level of usefulness of the system

Evaluation of the system

For the attributes of simplicity, flexibility, acceptability, sensitivity, positive predictive value, representativeness, and timeliness

Description of the resources used to operate the system

Conclusions and recommendations

Figure 4 CDC guidelines for evaluating surveillance systems. ${ }^{2}$

and chronic morbidity associated with conditions studied. Such information was rarely available previously. For example, congenital varicella was thought to be extremely rare in Australia. However, the APSU study has provided an estimated incidence of 0.8 in 100000 births, similar to recent estimates from the UK. ${ }^{6}$

Although the APSU is not suitable as a sole source of mortality data, it can provide information on conditions with acute mortality (Kawasaki disease, congenital rubella, haemolytic uraemic syndrome), or where follow up studies of a cohort have been undertaken (extrahepatic biliary atresia, Rett syndrome).

Does the system stimulate epidemiological research likely to lead to control or prevention?

Preliminary results of the drowning/near drowning study showed differences between states, prompting development of state registers that will enable case control studies to examine prevention strategies.

The Rett syndrome study provided cohorts used for further research into associated skeletal abnormalities ${ }^{7}$ and for a randomised clinical trial of treatment.
Does the system identify risk factors associated with disease occurrence and/or lead to identification of prevention strategies? No case control studies to examine risk factors have yet been conducted through the APSU. Risk factors and prevention strategies have, however, been implicated in a variety of ways.

The extrahepatic biliary atresia study, using internal controls, confirmed late diagnosis was a risk factor for poor outcome. The need to educate health workers and parents to facilitate early diagnosis was highlighted as an important prevention strategy.

The haemolytic uraemic syndrome study identified several organisms, previously not implicated in Australia. Data contributed to the development of strategies for disease control and prevention, including: (1) changes to the code for the manufacture of fermented meat products; (2) requirement for notification of haemolytic uraemic syndrome cases to some state public health departments; (3) and public education about food storage and preparation.

Comparison with population data showed that children born in Australia in 1995 and 1996, whose mothers were born outside Australia, were at increased risk of congenital rubella. Establishing the vaccination status of this subgroup of women might prove to be an important preventive strategy.

Identification of cases exposed perinatally to human immunodeficiency virus (HIV)/AIDS has enabled a review of the uptake and efficacy of zidovudine treatment.

Does the system lead to improved clinical practice by health care providers who are the constituents of the surveillance system?

Of the 766 clinicians who responded to the questionnaire, $33 \%$ said information provided by the APSU had informed or changed their clinical practice; $62 \%$ found definitions and other information provided to be educationally useful, $52 \%$ had read APSU related publications, and $44 \%$ had seen conference presentations. Sixty eight per cent had read the last annual report and $70 \%$ of those found it useful. To date, publications containing APSU data or describing the system include 18 peer reviewed articles, one book chapter, two Masters of Public Health treatises, and seven annotations.

\section{Has the system led to changes in public health} policy?

Indirect measures of changes in public health policy were available from questionnaire responses. Thirty nine of 48 investigators said their study allowed evaluation of current medical management or policy, informed future medical management or policy, and/or contributed to prevention policy.

Of the 15 public health professionals who responded to the questionnaires, 12 had heard of the APSU. Two had received and read the annual report and both found it useful. Three had used information derived from APSU to formulate policies and best practice guidelines, to recommend future research, and/or to identify preventive strategies. 
Has the APSU provided a mechanism for national collaborative research?

Over 50 investigators were involved in the 15 studies conducted to the end of 1996 . Of these studies, 13 were multicentre and nine involved more than one state or territory. A wide variety of scientific disciplines were represented. Ninety per cent of investigators said their research could not have been conducted without national case ascertainment; $83 \%$ said this could not have been achieved without the APSU, and 90\% felt that "in retrospect, the APSU was the best way to conduct their study".

SIMPLICITY

The system is simple (fig 1). Report cards are easy to complete, requiring the clinician only to indicate the number of cases they have seen in the previous month or to tick the "nothing to report" box. Cards are reply paid (fig 2).

The APSU related workload for most clinicians is minimal. Of 766 clinicians, 670 $(88 \%)$ said they did not find it a burden to complete and return the monthly cards. By the end of 1996, nearly half had never reported a case, and a third had reported only one or two cases. The workload for clinicians reporting cases depended on the complexity of the study questionnaire. The proportion of clinicians who reported that questionnaires were "too long" ranged from none in the study of subacute sclerosing panencephalitis to $16 \%$ in the study of drowning/near drowning. The proportion who thought information requested was "hard to find" ranged from none in the study of severe combined immunodeficiency disorder to $39 \%$ in the study of acute flaccid paralysis.

FLEXIBILITY AND TIMELINESS

A new condition can be listed for surveillance within one month, the interval between mailings. However, a mailing to request notifica- tions could be performed within days in the case of an epidemiological emergency. The interval from receipt of a non-urgent study application to the condition appearing on the report card varied from three to 12 months. This is influenced by the requirement for a scientific review process, the time taken for modification required by reviewers, and the availability of space on the card. Case definitions of conditions can be changed within one month.

Ninety per cent of clinicians said they would report by telephone or fax if an important public health reason was provided. During the haemolytic uraemic syndrome epidemic, which occurred while this condition was under surveillance by the APSU, the system was sufficiently flexible to allow clinicians to make rapid contact by telephone. However, in the acute flaccid paralysis study (where telephone/ fax notification is requested so clinicians can be reminded of the requirement for stool testing for poliovirus), the number of notifications received by telephone/fax (32\%) rather than by card has been disappointing (Herceg A, personal communication). Reporting by electronic mail commenced in February 1997 and was used by 125 (14\%) reporting clinicians by May 1998. It is anticipated that this will increase as more clinicians gain access to email.

The length of time between notification of a case to the APSU, receipt of a questionnaire by the clinician, and receipt of a completed questionnaire by the investigator is important. We did not collect this data systematically, but 15 clinicians reported substantial time delay (up to seven months) between notification of a case to the APSU and receipt of a questionnaire from the investigator.

\section{ACCEPTABILITY}

Participation in APSU activities was used as an indicator of its acceptability. The average monthly card return rate increased from $88 \%$

Table 2 Comments from clinicians on the APSU mailing list in response to the question: "Any other criticisms or suggestions for improving the APSU?”

\begin{tabular}{|c|c|c|}
\hline Comment & Number & Percentage* \\
\hline Keep up the good work & 52 & 21 \\
\hline $\begin{array}{l}\text { Time delay between notification of a case to the APSU and subsequent contact for collection } \\
\text { of further clinical information is a burden and may compromise validity of data }\end{array}$ & 15 & 6 \\
\hline $\begin{array}{l}\text { Data collection is a burden; investigators should be more responsible for extracting individual } \\
\text { patient data }\end{array}$ & 13 & 5 \\
\hline $\begin{array}{l}\text { Acknowledgment of the contribution of reporting clinicians should have more prominence in } \\
\text { publications emanating from the APSU or studies conducted through it }\end{array}$ & 12 & 5 \\
\hline Mailing should be less frequent than monthly & 9 & 4 \\
\hline Problems with physician recall might affect data validity & 8 & 3 \\
\hline $\begin{array}{l}\text { There should be more feedback from the APSU regarding its findings, distribution of } \\
\text { continuing education type material, and objective evidence of its value. Request for more } \\
\text { publications in peer reviewed journals }\end{array}$ & 6 & 2 \\
\hline Some common conditions should be included on the monthly card & 6 & 2 \\
\hline $\begin{array}{l}\text { There is potential for under-reporting by some clinicians because of assumption in some cases } \\
\text { that others will report }\end{array}$ & 5 & 2 \\
\hline $\begin{array}{l}\text { Keep surveillance of conditions to defined length of time and cease surveillance after } \\
\text { predefined objective is reached. Include more conditions of public health relevance }\end{array}$ & 5 & 2 \\
\hline $\begin{array}{l}\text { Disagreement with case definition or diagnostic terminology; suggest more involvement of } \\
\text { related subspecialists in development of case definition }\end{array}$ & 4 & 2 \\
\hline The APSU is a complete waste of time and money & 4 & 2 \\
\hline $\begin{array}{l}\text { Suggest ongoing monitoring of what is being reported monthly so that relevant trends (such as } \\
\text { early epidemic) can be identified }\end{array}$ & 3 & 1 \\
\hline $\begin{array}{l}\text { Amount of clinical detail requested following a positive report has discouraged further } \\
\text { reporting (includes request for stool samples) }\end{array}$ & 3 & 1 \\
\hline $\begin{array}{l}\text { Concern that access to or relevance of the APSU as a research tool is limited to individuals } \\
\text { based at university teaching hospitals }\end{array}$ & 3 & 1 \\
\hline No follow up was requested on cases reported to the APSU & 3 & 1 \\
\hline
\end{tabular}

$\star 248$ of 766 respondents provided comments; the proportion of the 248 who provided comments is shown. Some respondents provided more than one comment. Comments are summarised, in broad categories, in rank order of frequency. 
Table 3 Sensitivity ${ }^{\star}$ of case ascertainment through the APSU

\begin{tabular}{|c|c|c|c|c|c|c|c|c|c|}
\hline \multirow[b]{2}{*}{$\begin{array}{l}\text { Condition under } \\
\text { surveillance }\end{array}$} & \multicolumn{6}{|c|}{ Cases from other sources not ascertained by the APSU } & \multirow[b]{2}{*}{$\begin{array}{l}\text { APSU } \\
\text { cases }\end{array}$} & \multirow[b]{2}{*}{$\begin{array}{l}\text { Total } \\
\text { cases }\end{array}$} & \multirow[b]{2}{*}{$\begin{array}{l}\text { Sensitivity } \\
(95 \% C I)\end{array}$} \\
\hline & $\begin{array}{l}\text { Rett Syndrome } \\
\text { Association of } \\
\text { Australiat and } \\
\text { other sources }\end{array}$ & $\begin{array}{l}\text { Victorian } \\
\text { birth defects } \\
\text { register }\end{array}$ & $\begin{array}{l}\text { Communicable } \\
\text { Disease } \\
\text { Intelligence }\end{array}$ & $\begin{array}{l}\text { Australian } \\
\text { Hearing } \\
\text { Services }\end{array}$ & $\begin{array}{l}\text { NSW inpatient } \\
\text { data fuly } \\
\text { 1993-fune } 1994\end{array}$ & $\begin{array}{l}\text { Mandatory } \\
\text { notification } \\
\text { NSW Dec } \\
\text { 1996-May } 1997\end{array}$ & & & \\
\hline Rett syndrome $\ddagger$ & 49 & & & & & & 93 & 142 & $64 \%$ (57 to 73 ) \\
\hline Congenital rubella & & 0 & 0 & 1 & & & 12 & 13 & $92 \%(64$ to 100$)$ \\
\hline $\begin{array}{l}\text { Drowning/near } \\
\text { drowning } ₫\end{array}$ & & & & & 62 & & 28 & 90 & $31 \%(22$ to 42$)$ \\
\hline $\begin{array}{l}\text { Extrahepatic biliary } \\
\text { atresia }\end{array}$ & & & & & 1 & & 9 & 10 & $90 \%$ (56 to 100$)$ \\
\hline $\begin{array}{l}\text { Haemolytic uraemic } \\
\text { syndrome }\end{array}$ & & & & & & 1 & 4 & 5 & $80 \%$ (28 to 99$)$ \\
\hline
\end{tabular}

in 1993 to $93 \%$ in 1996 . Forty per cent said they would not return the card if it was not reply paid. The median return rate of study questionnaires was 92\% (range, 59-100\%). Between May 1993 and December 1996, 18 applications for studies were received.

Ninety two per cent of responding clinicians thought the number of conditions monitored was appropriate or could be increased; $67 \%$ reported "nearly always" or "always" reading study protocol sheets, while 5\% "never" read them. Thirty two per cent of clinicians provided comments in response to an open ended question asking for their opinion of the APSU and suggested areas for improvement (table 2). Requests for the provision of specimens diminished the acceptability of some APSU studies. Nine of 41 clinicians notifying cases of acute flaccid paralysis and 16 of 56 clinicians notifying cases of haemolytic uraemic syndrome said they objected to obtaining stool samples.

\section{SENSITIVITY}

As an indirect indication of sensitivity, $5 \%$ of clinicians on the mailing list reported returning cards with "nothing to report", despite knowledge of a case, assuming that other clinicians caring for the child would notify. In addition, $1 \%$ said that they had failed to return a card despite knowledge of a case.
To estimate the sensitivity of the APSU, cases were ascertained from alternative sources for five studies (table 3). Sensitivity ranged from $31 \%$ (drowning/near drowning) to $92 \%$ (congenital rubella). ${ }^{8}$

POSITIVE PREDICTIVE VALUE

Positive predictive value is defined as the proportion of notified cases who actually do have the condition under surveillance. ${ }^{2}$ Table 4 shows all cases reported to the APSU since 1993 and their status at the end of 1996. Positive predictive value ${ }^{2}$ can be calculated for the APSU in three ways. First, all duplicates and errors could be considered invalid and used in the denominator. However, the APSU encourages duplicate notification to maximise case ascertainment. Thus, alternative methods of calculating positive predictive value can either exclude duplicate reports or include them in the numerator. The use of these calculations produces quite different estimates of positive predictive value, as shown in table 4 . Using the latter two methods, most notifications had a positive predictive value above $70 \%$.

REPRESENTATIVENESS

Representativeness ${ }^{29}$ of the APSU could not be assessed directly because alternative sources of national case ascertainment do not exist for many conditions or are not comparable. There was minimal variation between response rates

Table 4 Positive predictive value (PPV) of cases notified to the APSU (May 1993 to December 1996)

\begin{tabular}{|c|c|c|c|c|c|c|c|c|c|}
\hline \multirow[b]{2}{*}{ Condition under surveillance } & \multirow{2}{*}{$\begin{array}{l}\text { Total } \\
\text { reports }\end{array}$} & \multicolumn{2}{|c|}{ Valid reports (n) } & \multicolumn{2}{|c|}{ Invalid reports ( $n$ ) } & \multirow{2}{*}{$\begin{array}{l}\text { Unknown } \\
\text { (n) }\end{array}$} & \multirow{2}{*}{$\begin{array}{l}P P V 1 \\
(\%)\end{array}$} & \multirow{2}{*}{$\begin{array}{l}P P V 2 \\
(\%)\end{array}$} & \multirow{2}{*}{$\begin{array}{l}P P V 3 \\
(\%)\end{array}$} \\
\hline & & Confirmed & Probable & Duplicates & Errors & & & & \\
\hline Acute flaccid paralysis & 77 & 54 & 0 & 16 & 1 & 6 & 70.1 & 88.5 & 90.9 \\
\hline Arthrogryposis multiplex congenita & 39 & 14 & 0 & 5 & 19 & 0 & 35.9 & 41.2 & 48.7 \\
\hline Childhood dementia & 223 & 92 & 24 & 6 & 10 & 91 & 52.0 & 53.5 & 54.7 \\
\hline Congenital adrenal hyperplasia & 80 & 32 & 0 & 38 & 3 & 7 & 40.0 & 76.2 & 87.5 \\
\hline Congenital and neonatal varicella & 49 & 35 & 0 & 6 & 7 & 1 & 71.4 & 81.4 & 83.7 \\
\hline Congenital rubella & 77 & 36 & 4 & 24 & 12 & 1 & 52.0 & 75.5 & 83.1 \\
\hline Drowning/near drowning & 495 & 250 & 0 & 37 & 76 & 191 & 50.5 & 54.6 & 58.0 \\
\hline Extrahepatic biliary atresia & 273 & 110 & 0 & 93 & 46 & 24 & 40.3 & 61.1 & 74.4 \\
\hline Haemolytic uraemic syndrome & 190 & 77 & 0 & 94 & 14 & 5 & 40.5 & 80.2 & 90.0 \\
\hline Haemorrhagic disease of the newborn & 65 & 15 & 2 & 16 & 13 & 19 & 26.2 & 34.7 & 50.8 \\
\hline HIV/AIDS & 189 & 90 & 0 & 71 & 9 & 19 & 47.6 & 76.3 & 85.2 \\
\hline Kawasaki disease & 366 & 149 & 0 & 41 & 66 & 110 & 40.7 & 45.8 & 51.9 \\
\hline Rett syndrome & 186 & 78 & 33 & 36 & 32 & 7 & 59.7 & 74.0 & 79.0 \\
\hline Severe combined immunodeficiency & 31 & 13 & 0 & 13 & 5 & 0 & 41.9 & 72.2 & 83.9 \\
\hline Subacute sclerosing panencephalitis & 8 & 4 & 0 & 3 & 1 & 0 & 50.0 & 80.0 & 87.5 \\
\hline
\end{tabular}

PPV1, all valid reports/total reports.

PPV2, all valid reports/(total reports - duplicates).

PPV3, all valid reports + duplicates/total reports. 
The evaluation has identified a number of ways in which the operation of the APSU may be improved

- Initiating systematic, more frequent revision of the mailing lis

- Improving dissemination of information to public health professionals

- Informing investigators of the variable sensitivity of the APSU and the potential benefits to studies of prospectively incorporating alternative methods of case ascertainment to allow calculation of sensitivity

- Improving study questionnaire response rates by limiting their length, sending questionnaires immediately on notification of cases by the APSU, and developing guidelines for investigators about appropriate follow up of notifications

- Restricting requests for telephone reporting and supply of biological specimens

- Encouraging acknowledgement of all contributors to the APSU on publications and presentations

Figure 5 Recommendations of the evaluation.

by state, territory (range, 90-97\%), or specialty group (range, $90-94 \%$ ) in 1996. This is an indirect indicator of representativeness.

RESOURCES USED TO OPERATE THE SYSTEM

The resources required to operate the APSU (the "direct costs"), comprise the personnel and financial resources expended in collecting, processing, analysing, and disseminating surveillance data. These currently total US $\$ 57$ 000/year (approximately £35 650), but this does not include salaries of the director and assistant director, or the costs incurred by investigators. Paid personnel include three part time administrators/data managers. There is currently no charge for investigators.

\section{Discussion}

Although the APSU fulfils most of its stated objectives and meets CDC guidelines salient to these, we identified areas where the operation of the system could be improved. We also identified methodological problems in applying CDC criteria to this type of surveillance unit.

The operation of the APSU is simple, acceptable to the mailing list, and sufficiently flexible to allow surveillance of acute conditions of public health importance. The usefulness of the APSU for monitoring such conditions pertains both to the system as a whole (encouraging national collaboration, improving clinical practice) and to specific studies. Although it was not designed to identify contacts or sources of infection of acute cases, and is not sufficiently timely to do so, the APSU is an important adjunct to the public health response. However, dissemination of information to public health professionals was identified as suboptimal. This and other limitations identified by this evaluation have resulted in the recommendations shown in fig 5 .

The attributes of direct relevance to the fulfilment of the APSU's primary objective, namely the sensitivity and representativeness of the system, were the most difficult to evaluate. One reason for this is that for studies accepted by the APSU there should be no alternative source of national case ascertainment. To calculate sensitivity, we used either national (Rett syndrome association, ${ }^{10}$ Australian Hearing Services), or state based sources (NSW inpatient data, NSW mandatory reporting). For most conditions, comparative data were only available for part of the surveillance period and were obtained by "passive" rather than "active" reporting. ${ }^{11-13}$ Limitations of using alternative sources include financial costs, pri- vacy issues, delay in gaining access to data, variable definitions, different age cut offs, and the fact that hospital inpatient statistics databases do not provide data for outpatients. ${ }^{14}$

Despite these limitations, sensitivity estimates for some studies were achieved and were generally satisfactory. The calculated values may reflect issues of poor data comparability as much as limitations of the APSU.

In situations where the APSU has been used to supplement other sources of case ascertainment, as in the HIV/AIDS study, ${ }^{15}$ the sensitivity of the system does not need to be high. For future studies with a high sensitivity requirement, APSU will recommend the prospective use of alternative sources of case ascertainment, either as a check of sensitivity or as a supplementary source of cases. Several British Paediatric Surveillance Unit studies have reached similar conclusions. ${ }^{16}{ }^{17}$ To overcome problems associated with sensitivity estimates, some systems have used complex statistical techniques, such as capture/recapture analysis, to estimate sensitivity. ${ }^{18}$ However, these depend on obtaining data from independent sources, which are often not available, and on the fulfilment of various assumptions, many of which are complex and untestable. ${ }^{19}$

A surveillance system that is representative accurately observes both the occurrence of a health event over time and its distribution by person and place in the population at any point in time. ${ }^{9}$ Uniform participation of clinicians by geographical distribution and speciality suggests that the APSU is representative. However, because no directly comparable data sources exist for the review of "missed" cases, there may never be a satisfactory means of assessing this factor. ${ }^{9}$

The APSU encourages notification of duplicate and "probable" cases (not fulfilling complete case definition) to maximise case ascertainment and information obtained. However, this has implications for calculation and interpretation of positive predictive value. A positive predictive value that allows for the incorporation of information about probable or duplicate cases is the most meaningful indicator of the value of a notification.

The success of a surveillance system depends on an appropriate balance of characteristics to meet its specific requirements. ${ }^{2}$ While explicit guidelines for the evaluation of surveillance systems have been developed by the CDC, not all of the suggested criteria are of equal importance, applicable to all components, or readily evaluable for the APSU. Equally, the appropriateness of the suggested measures in evaluating this type of surveillance unit was not straightforward.

Our evaluation has helped prioritise attributes such as sensitivity, which are directly relevant to the specific objectives of the APSU, while giving lesser weight to others that are less central to the achievement of those objectives.

Currently, the APSU's direct operating costs are moderate and it could be argued that the system, which facilitates simultaneous research into several conditions, is cost effective. ${ }^{17}$ Indirect costs, costs of secondary data sources, and 
costs averted by surveillance (savings resulting from preventing morbidity through surveillance data) are difficult to identify and quantify. Methods for formal cost benefit analyses of surveillance systems need to be developed. Such information will not only enhance the completeness of any evaluation, but will be increasingly necessary to secure funding for the maintenance of the operation of such systems in the future.

We thank clinicians contributing to the APSU, investigators for supplying data, Dr J Peat for statistical advice, Ms S Mildenhall for preparation of the manuscript and the Financial Markets Foundation for Children and the National Centre for Disease Control (Department of Health and Family Services) for financial support.

1 Hall SM, Glickman M. The British Paediatric Surveillance Unit. Arch Dis Child 1988;63:344-6.

2 Klaucke D, Buehler J, Thacker S, et al. Guidelines for evaluating surveillance systems. Morb Mortal Weekly Rep 1988; 37(suppl 5):1-18.

3 Elliott EJ, Williams K. Communicable diseases and the Australian Paediatric Surveillance Unit. Commun Dis Rep Australian Paediatric Surve

CDR Rev 1997;7:R14-16.
4 Elliott EJ, Chant KG. Rare disease surveillance. 7 Paediatr Child Health 1994;30:3-5.

5 Elliott E, Henning P, Hogg G, et al. Haemolytic uraemic syndrome in Australia 1994-5. Commun Dis Intell 1995 19:310-12

6 Forrest JM, Burgess MA. Plotting the demise of congenita rubella and varicella [editorial]. Australian and New Zealand fournal of Public Health 1996;20:4-6.

7 Leonard H, Thomson M, Bower C, Fyfe S, Constantinou J. Skeletal abnormalities in Rett syndrome: increasing evi- dence for dysmorphogenetic defects. Am 7 Med Genet 1995;58:282-5.

8 Burgess MA, Forrest JM. Congenital rubella in Australia: 1993 and early reports for 1994. Commun Dis Intell 1995;19:234-8.

9 Thacker SB, Parrish RG, Trowbridge FL. A method for evaluating systems of epidemiological surveillance. World Health Stat $O$ (published erratum appears in World Health Stat Q 1989;42:preceding 58) 1988;41:11-18.

10 Leonard H, Bower C, English D. The prevalence and incidence of Rett syndrome in Australia. Eur Child Adolesc Psychiatry 1997;6:8-10.

11 Vogt RL, LaRue D, Klaucke DN, Jillson DA. Comparison of an active and passive surveillance system of primary care providers for hepatitis, measles, rubella, and salmonellosis in Vermont. Am $\mathcal{F}$ Public Health 1983;73:795-7.

12 Hinds MW, Skaggs JW, Bergeisen GH. Benefit-cost analysis of active surveillance of primary care physicians for hepatitis A. Am f Public Health 1985;75:176-7.

13 Roberts C, Manning W, Chant K. Meningitis surveillance. NSW Public Health Bulletin 1992;3:97-101.

14 Royle J, Williams K, Elliott E, et al. Kawasaki disease in Australia 1993-1995. Arch Dis Child 1998;78:33-9.

15 McDonald AM, Cruickshank M, Ziegler JB, Elliott EJ, Kaldor JM. Perinatal exposure to HIV in Australia, 19821994. Med f Aust 1997;166:77-80.

16 Booy R, Heath PT, Slack MP, Begg N, Moxon ER. Vaccine failures after primary immunisation with Haemophilus influenzae type-b conjugate vaccine without booster. Lancet 1997;349:1197-202.

17 Godward S, Dezateux C. Validation of the reporting bases of the orthopaedic and paediatric surveillance schemes. Arch Dis Child 1996;75:232-6.

18 Wadsworth E, Shield J, Hunt L, Baum D. Insulin dependent diabetes in children under 5: incidence and ascertainment validation for 1992. BMF 1995;310:700-3.

19 Papoz L, Balkau B, Lellouch J. Case counting in epidemiology: limitations of methods based on multiple data sources. Int f Epidemiol 1996;25:474-8. 